REVISTA DE DERECHO UNED, NÚM. 7, 2010

\title{
RUTA JACOBEA, JUS COMMUNE Y JUS EUROPEUM
}

\author{
GaBriel García CANTERo \\ Catedrático Emérito de Derecho Civil
}

\begin{abstract}
El Estatuto medieval del Peregrino a Santiago vino a ser una manifestación del «Ius commune» que ha llegado hasta el siglo XXI. Representa, en cierto modo, un anticipo del actual Derecho comunitario (ciudadanía europea, protección del usuario de las vías de comunicación, asistencia hospitalaria internacional etc). Se han ampliado y diversificado las motivaciones subjetivas de los peregrinos, pero subsisten sus motivaciones religiosas en sentido amplio. Hoy en día, el Camino de Santiago es factor de europeización y prueba evidente de las raíces cristianas de Europa.
\end{abstract}

Palabras-Clave: «IUS COMMUNE», Código del Peregrino a Santiago, Ciudadanía europea, Protección de consumidores, Raíces cristianas de Europa.

Abstract: The medieval Statute of the Pilgrims to Santiago de Compostela came to be a demonstration of the "Ius commune» that has arrived at our days. It represented an advance of the current European Law (European citizenship, Protection of road user, international hospital assistance, etc). They have been expanded and diversified the motivations of the Pilgrims, but they subsit the religious motivations in extensive sense. The "Ruta Jacobea» is today a factor of europeanization and sign of the christian Roots in Europa.

Key Words: «Ius commune», Statute of the Pilgrims to Santiago, European citizenship, Protection of consumers, Christian Roots of Europa.

Sumario: 1. Pórtico: Por qué escribir sobre el Camino sub specie iuris.- 2. Origen, desarrollo y razón de ser de las peregrinaciones jaco- 
beas.- 3. Significado y frutos del Camino en los Reinos españoles durante la Reconquista.- 4. Tipología de los peregrinos o romeros.- 5. $¿$ ¿Hacia un Estatuto de los peregrinos? Algunos elementos que lo componen: A) El sujeto de la peregrinación. Desarrollo tardío del concepto de Ius gentium romano. B) Fuentes legales. Privilegios y exenciones. C) Protección penal y civil de los peregrinos o romeros. D) Medidas ulteriores para prevenir el fraude y la picaresca a lo largo del Camino: Los falsos peregrinos. 6. Colofón.

1. El autor de este trabajo, en su ya lejana juventud, dirigió a medio centenar de jóvenes europeos que integraban una de las Rutas de Pax Christi ${ }^{1}$ que convergieron en Santiago, en el verano de 1965. Luego resultó, -por mero azar de las antiguas oposiciones-, que también fue destinado a esta Universidad al obtener una cátedra de Derecho Civil en $1967^{2}$. Y cuando el Camino todavía era escasamente frecuentado, hizo en compañía de su esposa y de sus tres hijos menores de edad, por etapas anuales y a pie, la peregrinación familiar partiendo de Somport (Camino aragonés), siguiendo una de las rutas tradicionales (Logroño, Burgos, León, Astorga, Ponferrada, etc.), y penetrando en Galicia por el Cebreiro, conforme a la ruta clásica de Triacastella, Portomarín y Arzúa, nos permitió finalmente abrazar al Apóstol en Santiago. Creo que lo anterior me da algún título para glosar el enjundioso estudio histórico-jurídico ${ }^{3}$ que hace poco tiempo elaboró -yo diría que amorosamente-, el Prof. D. Antonio Fernández de Buján, catedrático de Derecho Romano de la Universidad Autónoma de Madrid, dado que, por lo demás, carecería yo de cualquier legitimación, ni como historiador ni como romanista, para enjuiciarlo. Añado que, a mi juicio, si en los siglos medios el Camino Francés constituía un modo de dar visibilidad al Jus commune, en el

\footnotetext{
${ }^{1}$ Pax Christi es un Movimiento católico internacional, surgido entre las ruinas de la Segunda Guerra Mundial, para tratar de superar, desde un punto de vista religioso, (católicos lucharon en ambos bandos), la tradicional enemistad germano-francesa por consecuencia de tres enfrentamientos bélicos en menos de un siglo, ulteriormente transformado en un Movimiento dirigido a sentar las bases de la paz entre todos los países, siguiendo las pautas de Pío XII, Pablo VI. y Juan XXIII. Entre sus instrumentos formativos figuraba la realización anual de Rutas o marchas internacionales a pie, con jóvenes de diversos países europeos, que, al cabo de varios días, convergían en algún santuario famoso (el Puy, Oropa, La Folgöet, Flüeli, Santiago, etc.).

${ }^{2}$ Como creyente no puedo de dejar de ver providencial el hecho de que, por circunstancias de la vida, viviera mis última etapa de vida activa universitaria en la Universidad de Zaragoza, la Ciudad Inmortal tan ligada a la predicación del Apóstol en la Hispania romana.

${ }^{3}$ El Camino de Santiago: Estatuto jurídico del peregrino compostelano, en el vol. «Estudios Jurídicos in memoriam del Profesor A. Calonge». Asociación Iberoamericana de Derecho Romano. Vol. 1, págs. 353-373. (Salamanca 2002).
} 
momento actual, aparte del amplio abanico de posibles motivaciones subjetivas de quienes lo emprenden, el mero hecho de convivir en el iter jacobeo muchos romeros de la Europa políticamente unida - y aun de otros continentes -cada año más numerosos, el nuevo fenómeno podría simbolizar asimismo la decidida voluntad de construir o reconstruir-, una Unión Europea fiel a sus orígenes y a sus raíces cristianas, e, incluso, hasta instalar las primeras piedras de ese Global Law que algunos romanistas propugnan también entusiásticamente ${ }^{4}$.

Mis reflexiones van a girar en torno al trabajo citado, y conviene, por ello, exponer aquí su sistemática interna, bien estructurada por lo demás:

1. Perspectiva histórica.

2. El Camino como vínculo de interrelación entre las naciones europeas. Santiago y América.

3. Tipología de las peregrinaciones.

4. Estatuto jurídico de los peregrinos:

4a) Peregrini y Ius gentium;

4b) Legislación eclesiástica y real específicas: Privilegios y excepciones;

4c) Especial protección del peregrino: Malos tratos. Robo. Testamento, Sucesión testamentaria. Sepultura, Enfermedad, Abadías y Hospitales.

Un análisis elemental de este sumario convence de que el Estatuto del peregrino no representó algo esporádico o coyuntural, algo ocasional o transitorio, sino una estructura jurídica destinada a pervivir en el tiempo con una evidente finalidad protectora de los peregrinos; y si nos trasladamos al Medievo advertimos de inmediato la evidente utilidad de aquél dada la situación, -no pocas veces, realmente vulnerable-, de quienes transitaban por la Ruta Jacobea.

2. Después de narrar los conocidos acontecimientos históricos que originaron las peregrinaciones al sepulcro del Apóstol Santiago en la catedral de Compostela, el Prof. A. Fernández de Bujan consta$\mathrm{ta}^{5}$ que «es un hecho histórico incuestionable que a partir del descu-

${ }^{4}$ DOMINGO, Principios de Derecho Global,(2003); Ex Roma Ius (Cizur Menor, 2005). Además de dirigir The Global Law Collection, en Thomson-Aranzadi, a la que pertenece la última obra citada.

${ }^{5}$ A. FERNÁNDEZ DE BUJÁN, op. cit. págs. 354 y s. 
brimiento de la tumba del apóstol en el siglo IX, muchedumbres de peregrinos $^{6}$, procedentes de todos los reinos de la Europa cristiana afluyen a Compostela, dando origen a la historia humana de la peregrinación y a la configuración del camino de Santiago, al que tan bien cuadra el conocido verso machadiano caminante, no hay camino, se hace camino al andar. La fijación definitiva de la terminología correspondiente se hace ya en esta época: peregrinus, peregrinare y peregrinatio». Fenómeno que, por lo demás, no ha sido único en la historia, ya que «el sepulcro del Apóstol en Compostela se convierte en un gran centro de peregrinación, al igual que lo habían sido en siglos anteriores, el sepulcro de Confucio en China, el Santuario de Delfos en Grecia, el Santo Sepulcro de Cristo en Jerusalén, la tumba del Apóstol Pedro en Roma o la tumba del Profeta Mahoma en Medina; su significación responde al replanteamiento de las eternas preguntas que de forma permanente han preocupado a la humanidad a lo largo de la historia y prueba la profunda influencia del espíritu en la vida de los pueblos ${ }^{7}$ «. Además, para España hay que recordar la idea de Sánchez Albornoz de que el culto a Santiago constituyó una fuerza galvanizadora de la resistencia de la Cristiandad frente al Islam. Añado por mi cuenta que les faits sont les faits, los cuales deben ser asumidos por todos, por más que acometamos en el siglo XXI, con mayor o peor fortuna, una aproximación entre civilizaciones diversas y dispares.

El Liber Sancti Jacobi oficializa el Camino francés dividido en trece etapas, pero existieron otros caminos secundarios -hecho que, a mi juicio, viene a corroborar su auténtico universalismo-, como el inglés, el portugués, el catalán, la ruta marítima de Arosa y Finisterre, la cantábrica y la calzada romana conocida como Vía de la Plata. Apostilla el autor ${ }^{8}$ que circunstancias diversas en la forma, pero en estrecha relación en el fondo, explican la gestación histórica y la adap-

${ }^{6}$ El propio autor hace una valoración sociológica del fenómeno: «Aunque el siglo XII constituye la época de mayor auge del Camino, grandes peregrinaciones en medio de un clima de fervor popular se producen a lo largo de los siguientes siglos XIII y XIV. El siglo XV y el XVI, quizás a consecuencia de los movimientos políticos que originan la configuración de las naciones modernas y del triunfo de la reforma protestante especialmente en Holanda, Alemania e Inglaterra, supone el comienzo de la decadencia del Camino, que experimenta una cierta revitalización en los siglos XVII y XVIII, a la que se refiere entre nosotros el Padre Feijoo. El XIX vuelve a ser un siglo de crisis, que se prolonga hasta la segunda mitad del siglo XX, que conoce una importante revitalización que paulatinamente vuelve a hacer del Camino de Santiago un referente religioso y cultural en Europa e Iberoamérica» (op. cit. pág. 354, nota 7).

${ }^{7}$ A. FERNÁNDEZ DE BUJÁN, op. cit. pág. 355.

${ }^{8}$ A.FERNÁNDEZ DE BUJÁN, op. cit. pág. 357. 
tación sistemática de una normativa jurídica, dictada para regular el status de los peregrinos que, de toda Europa, se ponían en marcha, con destino a la tumba del Apóstol Santiago. La idea del peregrinaje a un lugar santo, hacía que, en cierto sentido, llegara a ser, en íntima relación con la espiritualidad de la época, considerada sagrada la propia persona del peregrino, de ahí la interrelación de normas civiles y eclesiásticas, dirigidas a tutelar al peregrino durante el trayecto de ida y regreso ${ }^{9}$, mediante disposiciones específicas relativas a numerosos aspectos, que suponen privilegios para los peregrinos y agravación de responsabilidad para quienes, en relación con aquéllos, actuasen en contra de su persona o de sus intereses.

3. A mi juicio está muy lograda la síntesis que hace el autor ${ }^{10}$ al describir el Camino como vínculo de interrelación entre las naciones europeas, que -no lo olvidemos- permitió además a los cristianos españoles, durante los siglos oscuros de la invasión musulmana, asomarse y mantener contacto con la realidad de la Europa christiana, como modelo al que podían legítimamente aspirar.

La promulgación de normas comunes a todos los peregrinos jacobeos, con independencia de su nacionalidad, y su aplicación uniforme en los distintos reinos, supone una contribución esencial del Camino a la configuración del Derecho internacional privado. Por otra parte, la compenetración y armonización entre la legislación eclesiástica y civil que, en buena medida, constituye una de las características del medievo, se pone de manifiesto de forma especial en la legislación aplicable a los peregrinos, cuyo conjunto se ha denominado Código de los peregrinos (Valiña Sampedro). La normativa de la peregrinación afecta al peregrino desde antes de la partida, a través del trayecto de ida y vuelta a su lugar de residencia o, en su caso, al fallecimiento in itinere, y extiende sus efectos al tiempo posterior a su finalización. El vínculo de unión y la europeización de los territorios por los que discurre el Camino se manifiesta en aspectos tan diferenciados como la vestimenta común de los romeros, el florecimiento de abadías y hospitales a lo largo de la ruta, y la recepción y transmisión a través de los ciudadanos de las diversas naciones, la religiosidad, arte, cultura y elementos caracterizadores y de progreso propios de cada pueblo. La recíproca influencia entre la naciente

9 Todavía hoy no es infrecuente encontrar en el Camino a peregrinos extranjeros que regresan a pie a su país, haciendo el camino de vuelta (hábito, por cierto, infrecuente de los peregrinos españoles que regresan empleando distintos medios de transporte de los utilizados a la ida).

${ }^{10}$ A. FERNÁNDEZ DE BUJÁN, op. et loc. últim. cit. 
España y el continente europeo, es significativa. A través del Camino recibimos la difusión del arte románico, a cuyo florecimiento se contribuye con importantes aportaciones, los cantares de gesta, los cánticos de los juglares franceses, así como múltiples ideas, instituciones y costumbres propias del Occidente Europeo (el autor menciona también las creaciones literarias, filosóficas, científicas y artísticas de los musulmanes y cristianos españoles, la poesía galaico-portuguesa de las Cantigas del Alfonso X el Sabio, y las aportaciones arquitectónicas árabes al románico europeo). Puede considerarse, acaso, como otra aportación del Camino, la aparición de una clase media desconocida hasta entonces (mercaderes, artesanos, posaderos y cambistas). Por otra parte, el descubrimiento y evangelización del continente americano, desde finales del siglo XV, va a suponer al poco tiempo la llegada desde aquellas tierras, por vía marítima, hasta la península ibérica, de cierto número de peregrinos que, a título individual o en pequeños colectivos recorrerán el Camino a Santiago. Ello explica que, visibilizando el fenómeno, se dé el nombre del Apóstol hasta una treintena de importantes ciudades americanas ${ }^{11}$ (Santiago de Chile, Santiago de Cuba, Santiago de Quito, Santiago de Castro, Santiago de Almagro, Santiago de Compostela en México, etc.).

4. Si inicialmente la motivación religiosa del peregrino fue la determinante, resulta inevitable que, con el paso del tiempo, surjan otras finalidades y objetivos entre la masa de ciudadanos europeos que caminan hacia Santiago. El autor hace una exhaustiva tipología de los mismos, en alguna medida aplicable a los peregrinos actuales ${ }^{12}$, con el añadido de haber desaparecido prácticamente lo que el autor caracteriza de peregrinaciones no voluntarias, o forzosas. Partiendo de una inicial distinción entre peregrinaciones voluntarias (orationis causa o pietatis causa), usuales en los primeros siglos, y las peregrinaciones de una u otra forma forzosas, entre las que el autor diferencia:

a) peregrinación confesional, denominada en atención a su imposición al recibir el sacramento de la penitencia, como expiación por las faltas cometidas;

b) peregrinación penitencial impuesta por las autoridades gubernativas o por los jueces o tribunales eclesiásticos o civiles, como sanción por determinados delitos o que revistiesen una especial gravedad;

${ }^{11}$ HUIDOBRO Y SERNA, Santiago y América (Santiago de Compostela 1993).

${ }^{12}$ A. FERNÁNDEZ DE BUJÁN, op. cit. págs. 358-360. 
c) peregrinación realizada en nombre y representación de un pueblo o comunidad;

d) peregrinación testamentaria, por consecuencia de una herencia o legado en el que el testador ordenaba o rogaba al heredero o legatario, o a persona designada genérica o específicamente, que peregrinase a Santiago en sufragio del alma del testador o de sus parientes ${ }^{13}$;

e) Peregrinación votiva, es decir, en cumplimiento de una promesa o voto realizado por una persona, que puede proceder personalmente a realizar la peregrinatio, o hacerlo por medio de persona interpuesta;

f) Peregrinación por delegación, en los supuestos de personas que no podían o no querían realizarla personalmente.

Si se interroga a los actuales peregrinos sobre sus motivaciones, probablemente aparecerán otras muy diversas del Medievo: así algunos peregrinarán como forma de ejercicio físico o deportivo, o por practicar un turismo austero no consumista, o por curiosidad o espíritu de aventura, o por realizar nuevas experiencias de solidaridad, etc. Con todo son todavía muchos los peregrinos que actúan por motivaciones religiosas y aun por algún modo de singular espiritualidad, sin que pueda excluirse, acaso, no pocos de los que, a lo largo del Camino, en soledad o en contacto con otros compañeros ocasionales, han encontrado sentido a sus vidas.

5. La parte más extensa y enjundiosa del trabajo del Prof. A. Fernández de Buján es la dedicada al Estatuto jurídico del peregri$\mathrm{no}^{14}$, respecto del cual la doctrina se ha ocupado escasamente ${ }^{15}$, y que el autor sistematiza conforme a los aspectos subjetivos, fuentes legales, y contenido - de orden, fundamentalmente, civil y penal-, poniendo siempre de relieve sus raíces romanas y canónicas.

13 Cita a BERGANZA, Antigüedades de España, parte II (Madrid 1721) p. 218: «Usábase mucho en aquel tiempo el legado de las peregrinaciones a Santiago. Y del estilo, por ser tan ordinario, nació el dicho de que, en vida o en muerte, todos han de ir a Santiago».

${ }^{14}$ Op. cit. págs. 360-373.

${ }^{15}$ El autor cita, a pie de pág. nota 34, la siguiente bibliografía: GARRISON, À propos des pélerins et de leur condition juridique, en "Etudes Gabriel Le Bras», II (Paris 1965), nota 1. VALIÑA SANTIAGO, El camino de Santiago. Estudio histórico-jurídico, pág.14. GARCÍA y GARCÍA, La tutela legal de los peregrinos jacobeos (siglos XIV-XIX). Ruta internacional del Románico (siglo XIV), t. XVIII, 2000, págs. 115 y ss. ; y su Comunicación sobre La protección legal a los peregrinos en los Caminos de Santiago en los siglos $X I V$-XIX, al Congreso Internacional " I Giubilei nella storia della Chiesa» (Roma, junio 1999). 
A) La palabra peregrino ${ }^{16}$, de uso tan corriente en español, deriva inequívocamente de peregrinus que hacía referencia etimológicamente a quien, a través del campo -per agrum - llegaba a la Civitas romana, proveniente de otra comunidad política. Jurídicamente designaba a los extranjeros pertenecientes a pueblos comprendidos dentro del orbe romano, pero a los que no se reconocía la ciudadanía romana. La necesidad de regular las relaciones de los peregrinos entre sí y con los ciudadanos romanos, dio origen al ius gentium ${ }^{17}$. Considerado el ius civile como el derecho propio de la Civitas romana, las relaciones con otras comunidades, en origen latinas y con posterioridad itálicas y mediterráneas, hace necesario o bien el reconocimiento de los negocios realizados entre romanos y miembros de estas comunidades a través de la vía de la concesión del ius commercii o bien la formalización de tratados internacionales en los que se reconocía expresamente la validez de las relaciones comerciales a los ciudadanos de los pueblos firmantes. Sin embargo, la realidad de un tráfico comercial y económico cada vez más fluido hace necesario en el s. III a.d.C., la creación de una magistratura a la que se atribuye específicamente el conocimiento de los conflictos surgidos, especialmente en el ámbito de las relaciones patrimoniales, entre extranjeros y ciudadanos romanos y entre extranjeros entre sí. Esta institución se denominó pretura peregrina. A los miembros de la comunidades vinculadas o sometidas o que tengan simplemente relaciones comerciales con Roma, se les permite el acceso a negocios del ius civile no formalistas, se crean tipos especiales nuevos y se aceptan las instituciones y prácticas comerciales de esos pueblos que no chocan frontalmente con el viejo ius civile. Nace así propiamente un derecho del tráfico jurídico comercial, libre de formas, flexible, basado en la fi-

16 Véase también, A. FERNÁNDEZ DE BUJÁN, Derecho privado romano, $2^{\mathrm{a}}$ ed. (Madrid 2009) págs. 30-32.

${ }^{17}$ Ya se comprende que la bibliografía romanista especializada sobre el Ius gentium es considerable. El autor selecciona la siguiente: LAURIA, Ius gentium, «Fest. Koschaker», 1939, I, págs. 258 ss.; DE MARTINO, Variazioni postclassiche del concetto romano di ius gentium, "Annali Bari», 1947, VII-VIII, págs. 107 ss.; G. LOMBARDI, Sul concetto di «ius gentium» (Roma 1947); Diritto romano e ius gentium, SDHI, 16 (1959), págs. 254 ss.; FREZZA, Ius gentium, «Mélanges De Vischer», 1949, I, págs. 259 ss.; MICHEL, Sur les origines du «ius gentium», RIDA, 1956, págs. 313 ss.; BISCARDI, Le nuove frontiere del diritto, 1, 1979, págs 29 ss.; FERNÁNDEZ BARREIRO, El «ius gentium» como expresión de la identidad de la cultura romano-helenística, en el vol. «Derecho común y derechos nacionales en la tradición jurídica europea» (La Coruña 1991), pág. 22 ss.

Más amplia bibliografía, hasta 1972, puede consultarse en IGLESIAS, Derecho Romano. Instituciones de Derecho privado, 6ª ed. (Barcelona 1972), págs. 102 ss. notas 46 y 47. 
$d e s^{18}$, en la lealtad y corrección en el trato, que al final de la República ya se denomina ius gentium, utilizándose la vieja palabra gens, que designaba a los grupos suprafamiliares con un antepasado común, que tan importante papel jugaron en la Civitas primitiva .

El ius gentium no es un derecho de los extranjeros, sino un derecho accesible a los extranjeros, formado por instituciones romanas y no romanas, pero aceptadas estas últimas por los pueblos del mundo mediterráneo, de ahí que se hable en ocasiones de un pretendido derecho universal que no es tal en realidad, sino que es al universo romano al que se alude con la expresión. El nuevo proceso por el que se sentencian los litigios de derecho de gentes es el formulario que sustituye a las acciones de la ley. De derecho de gentes, en cuanto basados en la bona fides, se consideran los contratos consensuales (compraventa, arrendamiento, mandato y sociedad), la flexibilización de la sponsio, la sustitución de la mancipatio por la traditio, la inviolabilidad de los embajadores, etc. La fides entendida como lealtad, corrección en los tratos y respeto a la palabra dada, se convierte en el eje del nuevo derecho. La fides, con matiz subjetivo, que se objetiva por el magistrado en caso de conflicto y de ahí, quizás, la expresión bona fides, la razón natural (naturalis ratio) y la equidad se convierten en los ejes del nuevo derecho y en su fundamento filosófico.

Cicerón en De officiis, 3.17.69, nos dice que el ius gentium es ius civile. Y ciertamente lo es en cuanto se aplica en territorio romano, por magistrados romanos y está integrado en buena medida por instituciones y normas romanas. Pero hay que añadir a continuación que también instituciones, normas y prácticas nacidas en el seno del ius gentium, fueron primero utilizadas por los cives romani por su mayor flexibilidad y sencillez y posteriormente incorporadas al propio ius civile. Sintomático y significativo resulta el hecho de que el proceso formulario que nace para conocer conflictos del ius gentium, primero convive con el procedimiento propio de los cives romani, y después acaba por desplazarlo, convirtiéndose en el único utilizable para sustanciar los litigios del ius gentium y del ius civile.

${ }^{18}$ El autor cita bibliografía reciente: CREMADES, El «officium» en el Derecho privado romano (Madrid 1988); CASTRESANA, «Fides», "bona fides»: un concepto para la creación del Derecho (Madrid 1981); NÖRR, Die "fides» in römischen Völkerrecht (Heidelberg 1991).

Sobre la bibliografía más antigua: IGLESIAS op. et ed. cit. pág. 40, nota 7.

No se olvide que uno de los conceptos modernos más difícilmente asimilables por los países del Common Law, con vistas a una unificación europea, es, precisamente, el de la buena fe en las relaciones contractuales. 
Sentado lo anterior el autor prosigue ${ }^{19}$ que, sobre la base del ius gentium romano, en un proceso de aceptación o adaptación de normas provenientes de este cuerpo normativo, se configura el derecho del peregrino en la Edad Media, nacido, de forma semejante a la causa que fundamenta el origen del romano ius gentium, de la necesidad de regular las relaciones jurídicas que afectan a los peregrinos jacobitas, y con la particularidad -que no se daba en el ius gentium romano- de que la legislación medieval tiende no sólo a regular y proteger a los peregrinos sino que en buena medida también se caracteriza por privilegiarles y eximirles del cumplimiento de disposiciones de carácter general, hasta el punto de afirmarse por algún autor que los peregrinos no estaban obligados a la observancia de las leyes propias de los territorios por los que pasan, salvo las que tutelan el orden público y las que regulan la solemnidad de los actos ${ }^{20}$. En todo caso, el autor selecciona algunos pasajes de las fuentes romanas que han pasado al Estatuto del peregrino, ya sea literalmente, ya sea con leves retoques ${ }^{21}$.

${ }^{19}$ A.FERNÁNDEZ DE BUJÁN, El Camino de Santiago etc. cit. pág. 362.

${ }^{20}$ Cita a FERRARIS, Prompta Biblioteca (Romae 1766), s.v. Lex, art. III, 28, 43 y 45; y a BARBOSA, Collectanea Doctorum in Ius Pontificium Universum (Lugduni 1976) pág. 39.

${ }^{21} \mathrm{He}$ aquí la selección que hace el autor (op. cit. pág. 363 y notas 44 a 47):

D. 47.5.1 (Ulpianus, libro 38 ad edictum): «Se da acción contra los empresarios de naves, mesones y establos, si se dice que alguna de las personas de su dependencia ha cometido un hurto ...». 2 «La acción es al doble». 6. «El mesonero responde del acto de aquellos que tiene en su mesón para el servicio del mismo, y también de los que están allí hospedados; pero no del acto de los viajeros, porque no parece que el mesonero ni el establero puedan elegir ni rechazar al viajero que van de paso ...».

D. 4.9.1:(Ulpianus, libro XIV ad Edictum): "Dice el Pretor: Si los marineros, venteros y mesoneros no restituyesen lo de cualquiera que hubiesen recibido para que esté a salvo. daré acción contra ellos».

D. 4.9.5 (Gaius, libro V ad Edictum provinciale: «El precio que cobran el naviero, el mesonero y el establero no es el de la custodia, sino el naviero el de transporte de los pasajeros, el mesonero el de la estancia de los pasajeros y el establero el del acogimiento de las caballerías: sin embargo, quedan obligados por razón de custodia ... ". 1. «Todo lo que hemos dicho sobre el hurto debe entenderse también respecto al daño, pues no debe dudarse que el que asume algo bajo su custodia se entiende que no sólo garantiza por el hurto sino también por el daño».

D.4.9.6. pr. (Paulus, libro XXII ad Edictum): «Aunque gratis hubieres navegado o de balde te hubieres hospedado en la venta, no se te denegarán, sin embargo, las acciones por el hecho, si han sufrido algún daño con injuria». 3. "Con la acción por el hecho queda obligado el mesonero a causa de los que viven habitualmente en el mesón; pero esto se entiende a un huésped accidental, como es un viajero». ble».

D. 4.9.7.1 (Ulpianus, libro XVIII ad Edictum): «Esta acción por el hecho es al do-

C. 12.41.5.2 (Impp. Honorius et Theodosius AA. Ianni P.P.: «Concedemos ciertamente la sola hospitalidad con esta condición, que no se le pida al huésped nada de lo que se considera necesario para el alimento de los hombres o de los animales, y sea acelerado y continuo el viaje, y no le sea lícito a ninguno residir, para que la larga permanencia de los alojados no veje de ningún modo el predio. Será también castigado con la multa de diez 
La equiparación entre peregrinos y mercaderes se recoge en textos tanto de Derecho civil como de Derecho eclesiástico. Un Decreto de Gelmirez de 1113 equipara a mercaderes, peregrinos y romeros a efectos del derecho de prenda, lo que se confirma en el Derecho navarro (Fuero General de Navarra, libro III, t. 15, c. 27). También en las Partidas se equiparan peregrinos y mercaderes en ciertas situaciones, dando la preferencia a los primeros que van con intención de servir a Dios e ganar perdón de sus pecados e parayso ... mientras que los mercaderes andan con intención de ganar algo (Partidas, V, 8, 27). En relación con la libertad de circulación por los reinos españoles, se dispone en el Concilio de León de 1114, ratificado el mismo año en Compostela que negotiores et peregrini et laboratores in pace sint, et secure per terras eant ut nemo in eos, vel eorum res manos mittat. Me parece singularmente expresiva la disposición otorgada por Juan II de Castilla y León, en 1434 que era Año jubilar, con ocasión de un enfrentamiento entre mercaderes españoles y alemanes, dirigida: «Al Almirante mayor de la mar y a su subalternos y a todos los maestros et patrones et gentes de armas et capitanes de cualesquier naos et galeras et otras qualesquier fustas que andan por los mis mares ...et a todos los otros mis capitanes et gentes de armas que andan por las fronteras ... que por quanto este año es la perdonanza del Apóstol Santiago ... a su iglesia suelen venir, así por tierra como por mar muchas gentes de muchas partes ..., dexedes et consintades pasar libre et desembargadamente a todos et qualesquier que vinieren a dicha perdonanza por mar, o por tierra, así de los mis Reynos como de fuera dellos, et que les non prendales los cuerpos, ni les tomedes, nin embarguedes sus bienes, nin cosas por guerras que yo et los míos súbditos et naturales con ellos ayamos, nin por debdas que devan, ni por cosas algunas, asi en la yda et estada en la dicha Romería, como en la tornada della ... so pena de mi merced et de la privación de los oficios et de confiscación de los bienes ...». La Nueva y la Novísima Recopilación confirman, con pequeños matices las disposiciones contenidas en las Partidas ${ }^{22}$.

libras de oro cualquier funcionario, togado, alguacil, militar o caminante que en cualquier lugar le hubiere pedido alguna cosa al huésped. Porque de tal modo queremos sea desterrada la depravada costumbre, que no consentimos que quede sin castigo ni aun en los mismos que den algo, si se hubiere probado que espontáneamente dieron contra lo mandado alguna cosa».

${ }_{22}$ Véase la Nueva Recopilación I, 12, 1: «Todos los Romeros, y Peregrinos, que anduvieren en Romería por nuestros Reinos, mayormente los que fueren y vinieren en Romería a Santiago, sean seguros, i les damos i otorgamos nuestro privilegio de seguridad, para vayan y vengan, i estén ellos, y sus compañías por todos nuestros Reinos, seguros, que no les será hecho mal, ni daño, y defendemos que ninguno sea osado de les fazer fuerza, ni mal, ni otro daño; i yendo i viniendo a las dichas Romerías puedan seguramente alvergar y posar en Mesones, i lugares de alverguería, i Hospitales i puedan libremente comprar las cosas que ovieren menester ...». 
B) Fuentes legales. Privilegios y exenciones.

Sin que se pretenda invocar aquí un régimen similar al que actualmente rige entre los países de la UE que firmaron el Acuerdo Schengen sobre el paso fronterizo, conviene recordar que los peregrinos a Santiago se proveían, antes de iniciar el trayecto, de salvoconductos y certificados de peregrinación que les supondría una garantía de protección a lo largo del recorrido del viaje de ida, y de vuelta a sus países de origen ${ }^{23}$.

Ya se comprende que si se habla por algunos de un Código del peregrino, se hace en sentido no técnico, pues sus normas ni siquiera provienen de un legislador único; tampoco se ha hecho una mera Recopilación que hubiera facilitado su aplicación en épocas pretéritas, y actualmente su mejor conocimiento. Fundamentalmente proceden de los diversos reinos cristianos por lo que atraviesa el Camino, especialmente de los reinos españoles, y de la Iglesia Católica por tratarse de una actividad fundamentalmente religiosa. Se caracteriza por su casuismo ya que cada norma positiva suele tener por objeto un sector de la actividad que implica caminar hacia Santiago. La falta de un único poder legislativo que dicte la normativa de protección, facilita la aparición de algunas contradicciones internas.

Son numerosos los privilegios y exenciones concedidos por los reyes españoles ${ }^{24}$ : En 1072, Alfonso VI les exime del portazgo en Valcarce; en el Fuero de Daroca de 1142 se establece el plazo especial de un año para proceder a la partición de los bienes de una herencia, en el caso de que alguno de los beneficiarios hubiese marchado en peregrinación; en el Fuero de Alba de Tormes se concede el plazo especial de un mes para proceder a la declaración ante el juez en el caso de que la persona obligada o interesada estuviese peregrinando a Santiago; en el Fuero de Cuenca se suspende la acción dirigida contra un deudor que ha partido en peregrinación; en el Fuero de Navarra se prohíbe tomar en prenda los bienes de un deudor ausente por peregrinación; en varios Fueros se establece la exención de cauciones en la venta de un animal hecha por un peregrino; sabemos ya que el Decreto de Gelmirez (1113) prohíbe exigir prenda a los mercaderes, romeros y peregrinos, sancionando al que lo hiciera con el doble de la cosa empeñada.

Recuerda el autor que Fairén ha estudiado minuciosamente los juicios plenarios rápidos y el juicio de equidad, a fin de proteger a los

${ }^{23}$ A. FERNÁNDEZ BUJÁN, op. cit. pág. 365.

${ }^{24}$ A. FERNÁNDEZ BUJÁN, op. et loc. cit. 
romeros y peregrinos y facilitarles el trayecto ${ }^{25}$. Las Partidas se preocupan de la protección de los peregrinos en sus personas y bienes, especialmente en materia testamentaria ${ }^{26}$. En el debatido tema de las venta de cosas muebles, algunos Fueros disponen que cuando el comprador es un peregrino, adquiere la propiedad de modo definitivo sin que el propietario pueda redimirla pagando el precio ${ }^{27}$.

La Nueva y la Novísima Recopilación confirman, con pequeños matices, las disposiciones al respecto contenidas en las Partidas: «Todos los romeros y peregrinos, que anduvieren en romería por nuestros Reinos, mayormente lo que fueren y vinieren en romería a Santiago, sean seguros, i les damos i otorgamos nuestro privilegio de seguridad, para que vayan y vengan, i estén ellos, i sus compañías por todos nuestros Reinos, seguros, que no les será hecho mal, ni daño, i defendemos que ninguno sea osado de les fazer fuerza, ni mal, ni otro daño; i yendo i viniendo a las dichas romerías puedan seguramente alvergar y posar en mesones, y lugares de alverguería, i Hospitales y puedan libremente comprar las cosas que tuvieren menester»(Nueva Recop. I, 12, 1).

\section{C) Protección PENAL y CIVIL DE LOS PEREGRINOS.}

Si la protección penal se manifiesta en una mayor severidad para sancionar los delitos de que pueden ser objeto los peregrinos, la civil alcanza matices que hoy podemos aproximar a la legislación protectora de los consumidores (por ej. en materia de pesos y medidas falsas, calidad de alimentos y de la ropa de las habitaciones alquiladas).

El delito de robo al peregrino es regulado minuciosamente y se establecen penas muy severas tanto en la legislación civil como eclesiástica para los robos cometidos durante la ruta o en posadas; hay normativas que castigan con la horca el robo in itinere al peregrino (así el Fuero General de Navarra, V, 6,2 y VI, 4,2; y el Libro de los Fueros de Castilla), mientras que la legislación eclesiástica impone la

${ }^{25}$ A. FERNÁNDEZ DE BUJÁN, op. cit. pág. 366, con referencia a FAIRÉN, El juicio ordinario y los plenarios rápidos (Barcelona 1953) págs. 53 y ss.

${ }_{26}$ «Si acaeciere que algunos romeros, o los herederos dellos, que vinieren por razón de sus testamentos, o de sus bienes ante ellos, que los oygan luego, o los libren lo más ayna, e lo mejor que podieren o sopieren, sin escatima e sin alongamiento. De manera que su romería, nin su derecho, non se les embargue, por alongança de pleytos escatimosos, nin en otra manera que ser pueda» (Partida VI, Tít. I, Ley XXXI).

${ }^{27}$ Se citan los Fueros de Avilés y Oviedo, el Libro de los Fueros de Castilla y el Fuero de Soria. Entre la abundante bibliografía, menciona los conocidos trabajos de Melón Infante, García de Valdeavellano y José $\mathrm{M}^{\mathrm{a}}$ Miquel. 
pena de excomunión (Concilios Lateranense de 1123 y de Lérida de 1173). Cuando el delito se comete en las posadas, se imponen penas mayores que cuando la víctima no es un peregrino.

En materia de disposiciones mortis causa, se reconoce el derecho del peregrino a hacer testamento oral o por escrito, por Alfonso IX en 1226, confirmado por el Fuero Real, IV, 24,2 ${ }^{28}$. Hay variedad de disposiciones, a lo largo del tiempo, en relación con los sucesión ab intestato del peregrino. Desde el Decreto del Alfonso IX de 1226, modificado en 1228, pasando por el Decreto de 1354 de Alfonso X, los Fueros de Castilla, el Fuero Real y la Novísima Recopilación, prevaleciendo, en definitiva las disposiciones de la Partida VI, Tít. 1, Ley 31 que vuelve sustancialmente a las del Decreto de 1226 (el mesonero hereda el vestido principal del peregrino; si el peregrino tenía compañeros de viaje, del mismo país, se encargaba a éstos del enterramiento y exequias a cargo de los bienes del difunto, quedando asimismo obligados a la entrega de los bienes restantes a los herederos legales; en caso de no tener compañeros, el entierro y funeral se encargaban al hospedero y capellán y pagados estos gastos, el resto se distribuía ente el hospedero, el capellán y el rey), estableciendo otras normativas el interés de la guerra contra los moros, el alma del peregrino o, incluso, el del propio hospedero que le heredaba en su totalidad. Obsérvase, no obstante, que estas reglas sobre el peregrino que fallece intestado tenían escasa aplicación porque aquél había hecho testamento antes de partir, o in itinere, pues en los principales Hospitales había un Escribano dedicado a tal menester (el de San Marcos de León, el de Tabal del Camino en el Bierzo, o el de los Reyes Católicos en Santiago ${ }^{29}$.

D) Medidas PaRa PREVENIR El FRAUde Y La PICARESCA A LO LARGO DEL CAMINO: Los falsos PEREgrinos.

En determinado momento histórico la mayor afluencia de peregrinos hace nacer la picaresca en torno al Camino, permitiendo que se abusara de la buena fe de los habitantes de las poblaciones del trayecto, invocando por algunos una cualidad simulada para obtener beneficios fundamentalmente económicos. Iglesia y Estado han de in-

28 «Todo ome a quien no es defendido por derecho poder de fer manda de lo suyo, ca ninguna vale tano a los omes como ser guardadas sus mandas e por ende queremos que los romeros, quienquier que sean, e donde quier que vengan, puedan también en sanidad facer manda de sus cosas según su voluntad».

${ }^{29}$ FERNÁNDEZ DE BUJÁN, op. cit. pág.369, con cita de VALIÑA, El camino de Santiago, pág. 61. 
tervenir con normas de control y vigilancia, en beneficio de los auténticos peregrinos y del bien común de la sociedad.

En el siglo XVI las Cortes de Valladolid (1523), Toledo (1525), Madrid (1528) y Valladolid (1558) legislan para evitar el fraude y picaresca que, por entonces, rodea al Camino de Santiago, disponiendo que: «Los peregrinos y extranjeros que vinieren en romería a la Iglesia del Señor Santiago, pueden ir a la dicha Iglesia y romería, y tornar a sus tierras libremente, pidiendo limosna por su camino derecho, no andando vagabundos a pedir por otras partes, pues no se permite a los naturales del Reyno; y entiéndase que es camino derecho yendo por lugares que estén en el camino a quatro leguas, poco más o menos, a la una parte o a la otra del dicho camino; y porque no puedan pretender ignorancia de ésto, en los primeros lugares de frontera, por donde comúnmente entran o desembarcaren, las justicias manden a los mesoneros y hospitaleros que se lo digan y avisen de ello; y si les parece, lo hagan escribir y poner en una tabla en los mesones y hospitales; y lo mesmo se haga en la Iglesia del Señor Santiago (Nueva Recop. I, 30,6; Nov. Recop. I, 12,12). Muy curiosas son las Ordenanzas de Santiago de 1569 que limitan a tres días el máximo de estancia de los peregrinos en la ciudad, al cabo de los cuales se les expone en el rrollo durante cuatro horas, con amenaza de 200 azotes públicos si no salen inmediatamente a menos que se pongan a trabajar a las órdenes de un amo.

Minuciosa y reglamentista es la importante pragmática de Felipe II de 1590, en la que fija el hábito del peregrino y establece la necesidad de una licencia previa para recorrer la ruta jacobea: « En medio de estos males, ordenamos, mandamos y prohibimos que, en adelante, ninguna persona de estos reinos pueda traer el hábito de romero aunque sea para ir a alguna romería de nuestro reino. No pudiendo tampoco partir a las romerías sin la oportuna licencia de la justicia del lugar de su vecindad, en la que constará el día en que partió, edad y otros datos personales. El escribano las firmará para que puedan dar fe ante quienes lo requiriesen. En la licencia se hará constar además, que no pueden apartarse de su camino más de cuatro leguas. Llevarán también dimisorias firmadas y selladas por el Prelado de su domicilio. Permitimos que los extranjeros pueden entrar con los hábitos de romeros y peregrinos, siempre que trajesen las dimisorias de sus prelados. Mandamos que los justicias de estos reinos que estuvieren dentro de las cuatro leguas por donde entraren los extranjeros, que exijan que éstos se presentaren a ellos, obligándoles a que hagan constar ante escribano público su deseo de hacer peregrinación, que presenten a los Consejos de los lugares sus dimisorias 
y soliciten su oportuna licencia para poder continuar en romería, se les hará constar que no pueden apartarse más de las cuatro leguas del Camino. Españoles y extranjeros están obligados a llevar consigo las dimisorias de sus Prelados y las diligencias de sus Justicias, de lo contrario serán tenidos por vagabundos y sujetos a penas que la Ley impone contra ellos».

Similares disposiciones se dictan en otras ciudades europeas, como las Ordenanzas de Berna de 1523, y de Friburgo de 1565, encaminadas a distinguir entre auténticos y falsos peregrinos ${ }^{30}$. Luis XIV en 1768 todavía se ve obligado a ordenar que: «Ninguno de sus súbditos puede partir en peregrinación a Santiago de Galicia, Loreto $\mathrm{u}$ otros lugares fuera del reino sin licencia expresa de Su Majestad y «previa presentación a los Obispos de sus domicilios para que examinen los motivos que les inducen a peregrinar, de quienes recibirán la oportuna atestación por escrito, así como otros certificados del Alcalde, Secretario de Estado, etc., en los que constará el nombre, edad, cualidad, vocación, etc. los cuales certificados no se expedirán a los menores sin previo consentimiento de sus padres. Los que quebrantasen estas disposiciones serán castigados, por primera vez, con encarcelamiento, por segunda vez con azotes y por tercera vez a galeras y a ser tenidos por vagabundos. Todo lo cual es necesario urgir por interés público y seguridad general». Espíritu que también inspira a Carlos III , en su Ordenanza de $1775^{31}$, así como el R.D. del mismo monarca de 1783, y la Ley de 1818 de las Cortes de Navarra sobre las medias a adoptar en su territorio destinadas a proteger a los peregrinos y controlar los posibles excesos en la ruta a su paso por el territorio de su reino. La cuestión preocupa a los grandes escritores españoles de la época ${ }^{32}$.

${ }^{30} \mathrm{El}$ autor cita la siguiente obra: K.HAEBLER, Das Wahlfahrtsbuch des Hermannus Kunig von Vach und die Pilgerreisen der Deutschen nach Santiago de Compostela (Strasbourg 1899) pág. 83 (FERNÁNDEZ DE BUJÁN, op. cit. pág. 370, nota 98).

${ }^{31}$ Transcrita por FERNÁNDEZ DE BUJÁN, op. cit. pág. 372.

${ }^{32}$ Así el autor transcribe la siguiente cita de FEIJOO, Teatro crítico universal, IV, Discurso $5^{\circ}$ : Peregrinaciones sagradas y romerías, págs. 114-122: «He notado bastantes ejemplares de extranjeros que con la capa de devotos peregrinos son verdaderos tunantes, que de una parte a otra, sin salir de España y sin piedad alguna se sustentan a cuenta de la piedad ajena [ ... ] Gran número de tunantes, con capa de peregrinos, con el pretexto de ir a Santiago, comúnmente dan noticias individuales de otros santuarios de la Cristiandad, donde dicen que han estado; y visitar tantos santuarios para devoción es mucho, para curiosidad y vagabundería nada sobra». Obsérvese la perspicacia del escritor que contrapone la piedad del que da limosna a quien no se mueve por aquel sentimiento, $y$, por otro lado, avisa a quienes se ven deslumbrados por oír hablar de las maravillas de otros santuarios de la Cristiandad que muy difícilmente se habrán realmente visitado por devoción y más bien por curiosidad o vagabundería. 


\section{Colofón.}

La Ruta Jacobea es un fenómeno típicamente medieval que sigue manifestándose y desarrollándose en nuestros días. Fue indudablemente religioso en pleno apogeo de la Christianitas, y cabe decir que no se ha secularizado en su dimensión modernizada. Todavía hoy el modelo de Camino es el realizado a pie, o por la vía marítima oficializada, pero en la praxis se advierte la utilización de una gran variedad de medios de transporte, no excluyentes en sí mismos (caballería, bicicleta, moto, coche particular o de línea, ferrocarril, avión) y que pueden combinarse sin dificultad; pero la Iglesia compostelana exige un mínimo de recorrido a pie para calificar a los peregrinos. La evidente modernización de los últimos decenios, debida en buena parte a la actuación de las Comunidades Autónomas implicadas, ha supuesto restauración y mejora de los antiguos itinerarios, debidamente señalizados, así como apertura de nuevos caminos; igualmente desaparición de aquéllos por la construcción de autopistas y autovías. También una multiplicación de Centros de acogida a los peregrinos en los lugares más destacados y significativos del Camino. Salvo la restauración, y sucesiva transformación en hoteles del Hospital de los Reyes Católicos en Santiago, y del de San Marcos en León, puede decirse que los tradicionales y benefactores Hospitales de Peregrinos son hoy casi exclusivamente ruinas venerables. Durante los Años Santos, Galicia refuerza una especial vigilancia y asistencia en las rutas asiduamente utilizadas por los peregrinos. Igualmente se organizan eventos culturales.

Salvo en la mínima documentación que exigen las autoridades eclesiásticas para otorgar la Compostelana, o certificación de haber realizado la Ruta Jacobea, ya no puede hablarse de un Código del peregrino, al que, en cierto modo, ha venido a sustituir la ciudadanía europea. Se conserva la internacionalidad de los peregrinos, con predominio de los de origen europeo, incluso de países antes escasamente representados. Otras normas protectoras de romeros y peregrinos, en el trayecto y en su alojamiento o albergue, están conservadas y perfeccionadas en la vigente legislación comunitaria sobre protección de los consumidores, hoy en vía de codificación.

Si el nacimiento y desarrollo del Ius gentium en su etapa primigenia, representó un interesante fenómeno de recepción e integración parcial del derecho ajeno, llevada a cabo con gran inteligencia por el Derecho Romano, el Codex peregrinus facilitó las relaciones entre los diversos reinos cristianos europeos permitiendo ejercitar el ius communicationis que Vitoria y la Escuela española de Derecho Na- 
tural desarrollarán a partir de la Edad moderna. El Prof. D. Antonio Fernández de Buján no precisa exhibir sus credenciales de europeís$\operatorname{ta}^{33}$, siendo notorias sus notables aportaciones a temas jurídicos de actualidad (jurisdicción voluntaria, capacidad y discapacidad de las personas etc.).

${ }^{33}$ Baste consultar su reciente y excelente Ponencia: Ciencia jurídica europea y Derecho comunitario: "Ius romanum», "Ius commune», "Common law». "Civil Law», en las Jornadas de la UAM. de 2007 ( «Derecho privado europeo: Estado actual y perspectivas de futuro», págs, 69-219). 